\title{
THE ACTION OF 5-HYDROXYTRYPTAMINE ON THE NICTITATING MEMBRANE AND ON THE SUPERIOR CERVICAL GANGLION OF THE CAT
}

\author{
BY \\ U. TRENDELENBURG \\ From the Department of Pharmacology, University of Oxford
}

(RECEIVED NOVEMBER 18,1955$)$

An action of 5-hydroxytryptamine (5-HT) on the nictitating membrane has been described by several workers. Erspamer (1954) observed that in spinal cats the intravenous injection of 5-HT caused a larger contraction of the previously denervated nictitating membrane than of the normal. Reid and Rand (1952) observed that a contraction of the normal nictitating membrane was caused by injection of small amounts of 5-HT into the carotid artery. This suggested a direct action of 5-HT on the membrane, which was confirmed by Thompson (1955) in his experiments with the isolated nictitating membrane. Observations by Lecomte (1955) furthermore showed that the adrenal glands did not play an important part in the response of the nictitating membrane to intravenously injected 5-HT.

The first suggestion that 5-HT acted on autonomic ganglia was made by Gaddum and Hameed (1954), who obtained evidence for the view that this substance acted on tryptamine receptors present in the nervous tissues of the ileum of the guinea-pig. Robertson $(1953,1954 a)$ similarly obtained evidence for such an indirect action of 5-HT on the guinea-pig ileum, though he interpreted it as an action on the nerve endings. Robertson (1954a) also observed that 5-HT caused stimulation of the perfused superior cervical ganglion; this stimulating action was not blocked by hexamethonium (1954b).

The present work $\$$ was undertaken in order to obtain more information about the action of 5-HT on the superior cervical ganglion and on its effector organ, the nictitating membrane.

\section{METHODS}

Observations of the action of 5-HT on the normal and denervated nictitating membrane were made in spinal preparations 7-14 days after excision of the right superior cervical ganglion.
Perfusions of the heads of cats were made according to the procedure described by Burn and Trendelenburg (1954). This consists in principle in perfusing the head with a warmed mixture of 1 part of a $6 \%$ dextran solution and 3 parts of Locke solution through the carotid arteries, the outflow being collected from the external jugular veins. Injections were made into the perfusion fluid just before it reached the Y-piece, so that the injected material was evenly distributed to both sides.

For intra-arterial injections cats of 2-4 kg. were used. After inducing anaesthesia with ether, $80 \mathrm{mg}$./ kg. chloralose was injected intravenously. For intraarterial injections the lingual artery was tied and a cannula inserted pointing centrally. Injections were made when the external and internal carotid arteries were either occluded or left open. For the sake of brevity the first mode of injection will be described as "injection to the ganglion," the latter as "injection to the nictitating membrane," as earlier observations showed that an intra-arterial injection during occlusion of the external carotid artery acted on the superior cervical ganglion and not on the nictitating membrane (Trendelenburg, 1954).

Contractions of the nictitating membrane were recorded by attaching them to isotonic levers fitted with frontal writing points ; the contractions were magnified 7.5 times.

The cervical sympathetic chain was always divided. When electrical stimulation was necessary the peripheral end of the cervical sympathetic chain was placed on shielded electrodes and covered with warm liquid paraffin. Electrical stimuli of $0.7 \mathrm{msec}$. duration were applied at a rate of 2 or $15 / \mathrm{sec}$.

For intra-arterial injections carefully neutralized solutions were used, the injected volume never exceeding $0.2 \mathrm{ml}$. The following substances were used : 5hydroxytryptamine creatinine sulphate, nicotine hydrogen tartrate, hexamethonium bromide, atropine sulphate, mepyramine maleate, cocaine hydrochloride. All doses were expressed as salts. 


\section{RESUltS}

Intact Spinal Cat.-One to two weeks after excision of the superior cervical ganglion of the right side the response of the normal and of the previously denervated nictitating membrane to the intravenous injection of 5-hydroxytryptamine (5HT) was determined. The ganglion of the normal side was left intact, but the preganglionic fibres were cut. Results obtained in 7 spinal preparations showed clearly that the injection of $10 \mu \mathrm{g}$. 5-HT caused a much stronger contraction of the denervated than of the normal side, the ratio $D / N$ $\mu$ g. 5-HT into the perfusion fluid was found to cause a contraction of the normal nictitating membrane in 6 preparations, failing only in one experiment in which the injection was made very late. In three preparations the response of the previously denervated membrane to 5-HT was also determined, and it was found that it responded much more strongly than the normal membrane. This is shown in Fig. 1, where the response to the injection of $40 \mu \mathrm{g}$. 5-HT (HT) was compared with the response to $4 \mu \mathrm{g}$. noradrenaline $(\mathrm{N}), 1 \mathrm{mg}$. tyramine (T), and $10 \mu \mathrm{g}$. adrenaline (A). This

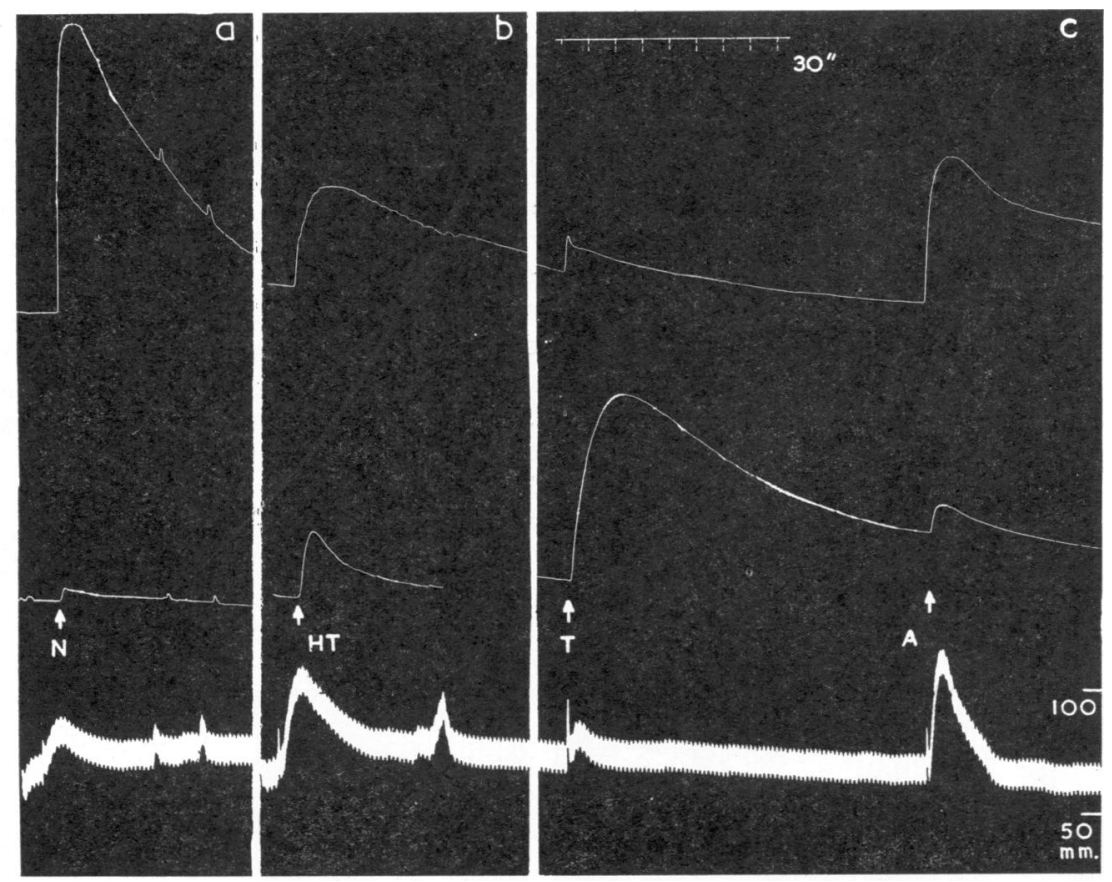

FIG. 1.-Perfused head of spinal cat. Denervated nictitating membrane (upper trace), normal nictitating membrane (middle trace) and perfusion pressure. Injection into the perfusion fluid of $4 \mu \mathrm{g}$. noradrenaline (N), $40 \mu \mathrm{g}$. 5-HT (HT), $1 \mathrm{mg}$. tyramine (T) and $10 \mu \mathrm{g}$. adrenaline (A). Interval of $3 \mathrm{~min}$. between (a) and (b) and of $2 \mathrm{~min}$. between (b) and (c).

being 3.44. After the intravenous injection of $30 \mu \mathrm{g}$. 5-HT the response of both membranes was increased, but the ratio fell to 1.13. After injection of 100 and $300 \mu \mathrm{g}$. 5-HT, however, the contraction of the normal side was usually greater than that of the denervated membrane, the mean ratios being 0.89 and 0.78 respectively.

Perfusion of the Head of the Cat.-In spinal preparations factors other than the direct action of a substance on the nictitating membrane may influence the response of this smooth muscle. The action of 5-HT was therefore studied in the perfused head of the cat. The injection of 10-100 example shows that 5-HT had a direct action on the nictitating membrane and that it resembled adrenaline rather than tyramine in its action, though it was less effective than adrenaline.

Stimulation of the Superior Cervical Ganglion.5-HT was injected intra-arterially through the central end of the lingual artery during occlusion of the internal and external carotid arteries (in the following described as "injection to the ganglion"). The dose ranged from 1 to $100 \mu \mathrm{g}$. in different experiments. This injection caused a contraction of the nictitating membrane of 17 out of 24 cats under chloralose anaesthesia $(=70 \%)$. 
In order to determine whether the contraction of the nictitating membrane observed after an injection of 5-HT to the ganglion was in fact due to stimulation of the ganglion, it was always compared with an injection of the same amount of 5-HT to the membrane (i.e., intra-arterial injection through the lingual artery when external and internal carotid arteries were left open). It was concluded that the response of the nictitating membrane to the injection to the ganglion was due to stimulation of the superior cervical ganglion for the following reasons:

(1) In sensitive preparations as little as 1-10 $\mu$ g. 5-HT caused a contraction of the nictitating membrane when injected to the ganglion, but not when injected to the membrane.

(2) Extirpation of the ganglion abolished the response to the intra-arterial injection to the ganglion.

(3) When the sensitivity of the ganglion was low, larger amounts of 5-HT $(10-100 \mu \mathrm{g}$.) had to be injected in order to obtain stimulation of the ganglion. These larger amounts had also a direct action on the nictitating membrane, making it more difficult to distinguish between a contraction in response to ganglionic stimulation and a contraction due to the direct action of 5-HT on the smooth muscle of the membrane. Fig. 3 shows, however, that the response to an injection to the ganglion $(x)$ was usually of shorter duration than the response to an injection to the membrane (o).
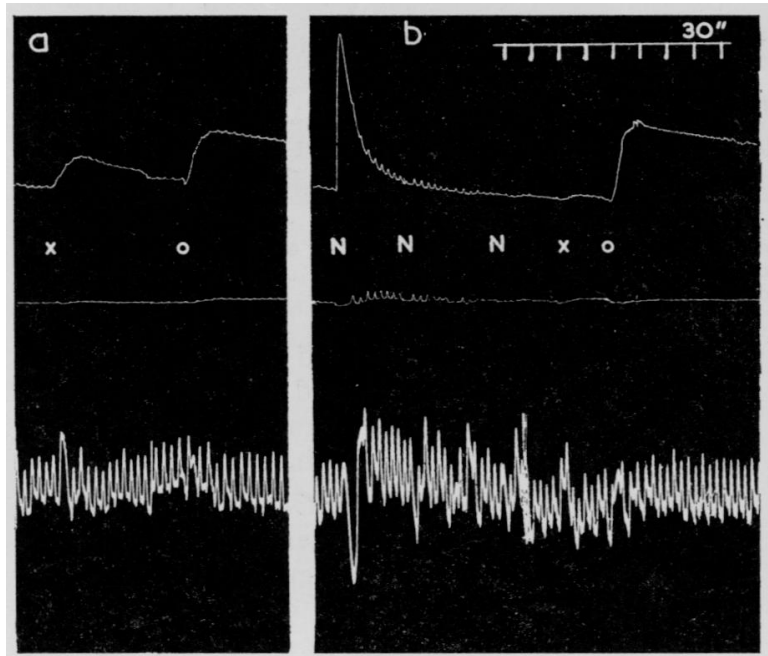

FIG. 2.-Cat under chloralose, $2.7 \mathrm{~kg}$. Nictitating membrane of the injected side (top trace), of the other side (middle trace) (both membranes normal), and arterial blood pressure (bottom trace). Intra-arterial injections of $50 \mu \mathrm{g}$. 5-HT to the ganglion (x) and to the nictitating membrane (o), in (a) before, and in (b) immediately after, three intra-arterial injections each of 100 ug. nicotine (N). Record (c) was obtained $30 \mathrm{~min}$. later.

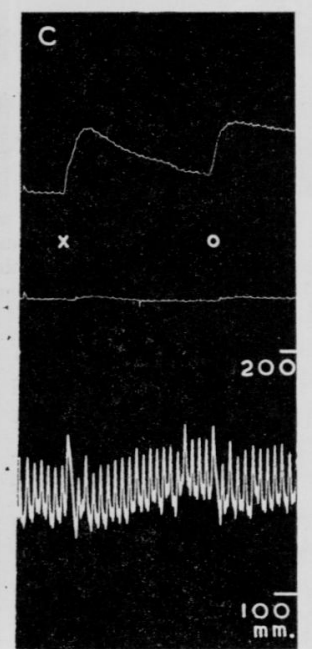

(4) When large amounts of 5-HT had to be injected, nicotine helped to differentiate the sites of action. Fig. 2 shows the response of the nictitating membrane to the injection of $50 \mu \mathrm{g}$. 5-HT, first to the ganglion ( $\mathrm{x}$ ) and then to the membrane (o). This was repeated $1 \mathrm{~min}$. after three successive injections of $100 \mu \mathrm{g}$. nicotine each, which blocked the action of $5-\mathrm{HT}$ on the ganglion but did not depress its action on the nictitating membrane (Fig. 2b). Thirty min. later 5-HT stimulated the ganglion again (Fig. 2c).

(5) The adrenal gland did not play any role in the response of the nictitating membrane, since the membrane of the other side did not contract (Fig. 2) and since adrenalectomy failed to change the response.

The action of a ganglion-blocking substance of the competitive type (hexamethonium) is illustrated in Fig. 3. It shows the response of the nictitating membrane to the intra-arterial injection of 100 $\mu$ g. 5-HT, first to the ganglion ( $x$ ) and then to the membrane (o), demonstrating the difference in duration of the responses. Fig. $3 b$ shows the repetition of the injections $3 \mathrm{~min}$. after an intravenous injection of $5 \mathrm{mg}$. hexamethonium, the responses being identical with the earlier ones. In 11 experiments hexamethonium was injected either intravenously $(5-20 \mathrm{mg}$.) or intra-arterially $(0.5-2 \mathrm{mg}$.$) , and these injections were found to$ produce complete block of ganglionic transmission. The response of the ganglion to 5-HT was, however, unchanged in 7 experiments, increased in one $(+28 \%$ of the initial contraction) and decreased in 3 experiments $(-28,-28$, $-40 \%$ ). Thus hexamethonium usually failed to block the stimulation of the superior cervical ganglion by 5 -HT.

A further differentiation between the actions of 5 HT on the ganglion and on the nictitating membrane was possible by the use of cocaine, which abolished or reduced the response of the ganglion to 5-HT when injected intravenously in amounts of 5-10 mg. Fig. 3c shows the response to the repetition of earlier injections 

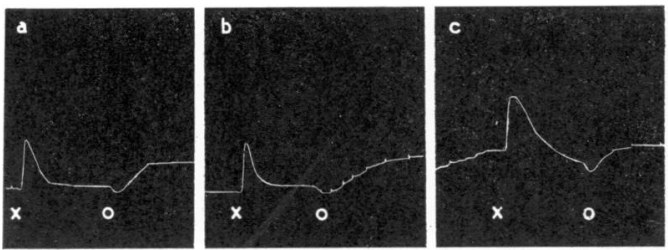

FIG. 3.-Cat under chloralose, $2.1 \mathrm{~kg}$. Normal nictitating membrane. Intra-arterial injections of $100 \mu \mathrm{g}$. 5-HT to the ganglion (x) and to the nictitating membrane (o). $30 \mathrm{~min}$. intervals between records; (b) was obtained $3 \mathrm{~min}$. after $5 \mathrm{mg}$. hexamethonium, (c) $5 \mathrm{~min}$. after $2 \mathrm{mg}$. cocaine, (d) $5 \mathrm{~min}$. after $6 \mathrm{mg}$. cocaine, all injected intravenously.

of 5-HT $5 \mathrm{~min}$. after the intravenous injection of $2 \mathrm{mg}$. cocaine. This amount of cocaine failed to modify the response, but after the intravenous injection of $6 \mathrm{mg}$. cocaine the response of the ganglion was abolished, while the direct action of 5-HT on the membrane was potentiated (Fig. 3d). The reduction of the action of 5-HT on the ganglion and the potentiation of its direct action on the membrane were observed regularly.

When atropine was injected in an amount which antagonized the response of the ganglion to pilocarpine, the response to an intra-arterial injection of 5-HT to the ganglion was found to be reduced, but such an amount of atropine was also found to reduce the response of the membrane to noradrenaline. The intravenous injection of $0.5 \mathrm{mg}$. mepyramine, on the other hand, did not affect the response of the ganglion to 5-HT, while abolishing that to histamine.

Desensitization to 5-HT by 5-HT itself was pronounced, necessitating time intervals of 10 to $30 \mathrm{~min}$. between two injections of 5-HT, in order to obtain a similar response to the second injection. Before testing the action of the abovementioned substances on the stimulation of the ganglion by 5-HT the right time interval was always determined.

Potentiation of Ganglionic Transmission.-As the results hitherto described suggested that 5-HT had ganglionic actions very similar to those of histamine and pilocarpine (Trendelenburg, 1954), its action on ganglionic transmission was investigated. When the preganglionic fibres of the ganglion were stimulated submaximally for $5 \mathrm{sec}$. twice per min. at a frequency of 2 shocks/sec., a series of contractions of the nictitating membrane was obtained as shown in

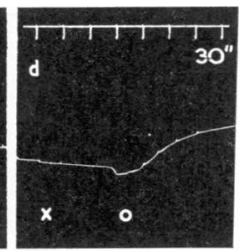

Fig. 4 (b to g). The intra-arterial injection to the ganglion of $0.2 \mathrm{ml}$. saline solution and of $0.001 \mu \mathrm{g}$. 5-HT failed to change the response to electrical stimulation (Fig. 4b). When, however, increasing amounts of 5-HT were injected to the ganglion, potentiation of the response became more and more pronounced. When expressing the potentiation as $\%$ of the initial height of contraction, it was found to be $50 \%$ for $0.01 \mu \mathrm{g} ., 115 \%$ for $0.1 \mu \mathrm{g}$., $190 \%$ for $1 \mu \mathrm{g} ., 190 \%$ for $10 \mu \mathrm{g}$., and $213 \%$ for $100 \mu \mathrm{g}$. 5-HT. The response to the nictitating membrane did not significantly increase when the dose of 5-HT was increased from 1 to 10 and even to $100 \mu \mathrm{g}$., but comparison with the response to supramaximal stimulation (Fig. 4a) shows that the injection of $1 \mu \mathrm{g}$. 5-HT increased the response to nearly maximal height. The greater effect of
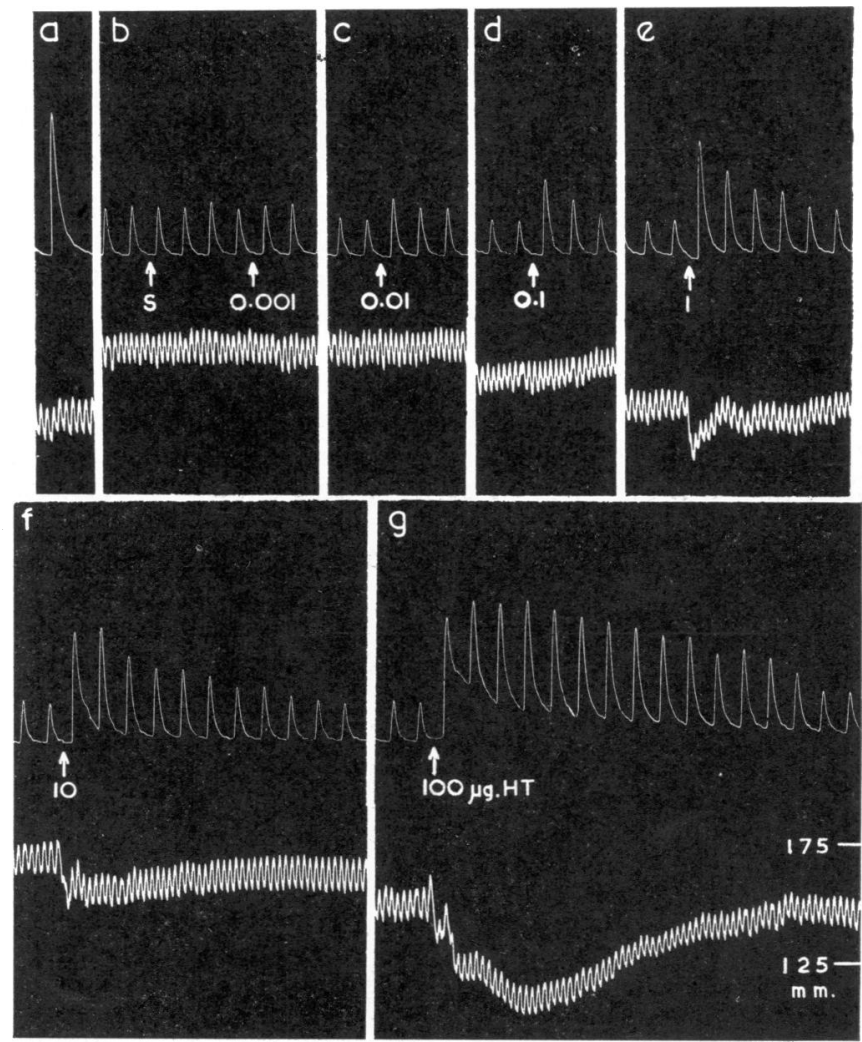

FIO. 4. Cat under chloralose, $2.1 \mathrm{~kg}$. Normal nictitating membrane and arterial blood pressure. Preganglionic stimulation for $5 \mathrm{sec}$, twice per $\mathrm{min}$, at a rate of $2 / \mathrm{sec}$. with supramaximal strength in (a) and submaximal strength in (b-g). Intra-arterial injections to the gangllon of $0.2 \mathrm{ml}$. saline and of $0.001 \mu \mathrm{g}$. 5 -HT in (b), of $0.01 \mu \mathrm{g}$. in (c), $0.1 \mu \mathrm{g}$ in (d), $1 \mu \mathrm{g}$. in (e), $10 \mu \mathrm{g}$. in (f), and $100 \mu \mathrm{g} .5-\mathrm{HT}$ in (g). 
increasing doses of 5-HT was, however, shown by a prolonged duration of the potentiating action. Fig. 4 also shows that the injection of 10 and $100 \mu \mathrm{g}$. 5-HT caused a contraction of the nictitating membrane. These larger doses therefore not only potentiated ganglionic transmission but also stimulated the ganglion cells themselves. Furthermore, in spite of the stimulation of the ganglion by a large dose of 5-HT there was no nicotine-like paralysis.

The response to supramaximal stimulation of the preganglionic fibres was not potentiated. Fig. 5 shows an experiment in which the intra-arterial injection of $10 \mu \mathrm{g}$. 5-HT potentiated the response to submaximal stimulation (a), failed to excite the unstimulated ganglion (b) and also failed to change the response to supramaximal stimulation (c). A potentiating action of 5-HT was also observed, when submaximal preganglionic stimulation was applied continuously instead of intermittently.

As the potentiation of the effect produced by submaximal preganglionic stimulation could have been caused by a lowering of the threshold of the nerve by 5-HT, the cervical sympathetic chain was split longitudinally in some experiments and a portion of the preganglionic fibres was stimulated supramaximally. This operation excluded any effect of 5-HT on the nerve threshold, but it provided a submaximal stimulus to the ganglion. A similar potentiation was observed under these conditions.

The action of atropine, mepyramine, and cocaine on the potentiation of ganglionic transmission by 5-HT is shown in Fig. 6. Throughout the experiment the same submaximal preganglionic stimulation and the same intra-arterial injection of $1 \mu \mathrm{g}$. 5-HT was used. The effect of 5-HT was not

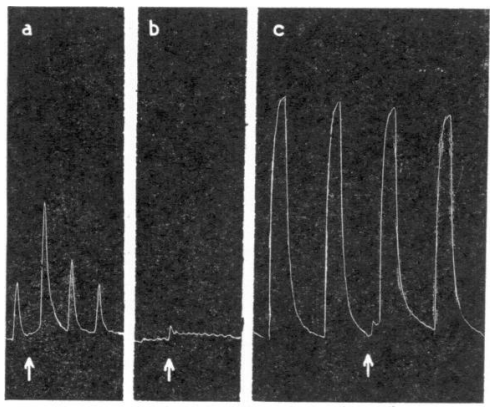

Fig. 5.-Cat under chloralose, $3 \mathrm{~kg}$. Normal nictitating membrane. Intra-arterial injections to the ganglion of $10 \mu \mathrm{g}$. 5-HT at arrow, (a) during submaximal preganglionic stimulation as in Fig. 4 but rate of stimulation $15 / \mathrm{sec}$., (b) without stimulation, (c) during supramaximal stimulation of the preganglionic fibres for $15 \mathrm{sec}$. once per min.
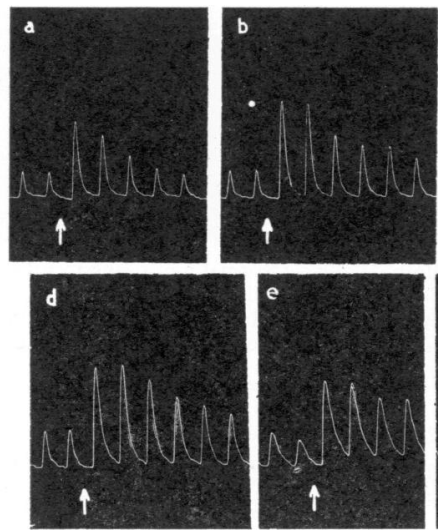

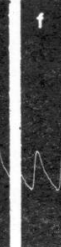

FIG. 6.-Cat under chloralose, $2.1 \mathrm{~kg}$. Normal nictitating membrane. Submaximal preganglionic stimulation for $5 \mathrm{sec}$. twice per min. Rate of stimulation $2 / \mathrm{sec}$. Intra-arterial injection to the ganglion of $1 \mu \mathrm{g}$. 5-HT at arrow. Time interval between records $20 \mathrm{~min}$. The following intravenous injections were made $5 \mathrm{~min}$. before the records: $400 \mu \mathrm{g}$. atropine before (b), $500 \mu \mathrm{g}$. mepyramine before (c), $1 \mathrm{mg}$. cocaine before (d), $4 \mathrm{mg}$. cocaine before (e), $8 \mathrm{mg}$. cocaine before (f).

depressed by a previous intravenous injection of $400 \mu \mathrm{g}$. atropine (Fig. 6b), nor of $500 \mu \mathrm{g}$. mepyramine (Fig. 6c), nor of $1 \mathrm{mg}$. cocaine (Fig. 6d). After $4 \mathrm{mg}$. cocaine (Fig. 6e), however, and especially after the intravenous injection of $8 \mathrm{mg}$. cocaine (Fig. 6f), the response to 5-HT was clearly reduced.

\section{Discussion}

When 5-hydroxytryptamine (5-HT) was injected intravenously into spinal preparations, observations slightly different from those of Erspamer (1954) were made. While the height of the contractions of the previously denervated nictitating membrane increased with increasing doses of 5-HT, the contractions of the normal membrane increased at a different rate, being comparatively smaller after the injection of 10-30 $\mu \mathrm{g}$. 5-HT, but exceeding the contractions of the denervated membrane after injections of 100-300 $\mu \mathrm{g}$. 5-HT.

This change in ratio was not observed in the perfused head. In this preparation 5-HT was always found to be more active on the denervated side; its action was similar to that of adrenaline. Thus 5-HT had a direct action on the smooth muscle of the nictitating membrane, an action which has also been observed by Thompson (1955), who found that 5-HT stimulated the isolated preparation of the nictitating membrane.

Further experiments showed that this direct action of 5-HT on the membrane was potentiated by cocaine, thus providing another example for the view expressed by Fleckenstein and Bass (1953) 
that cocaine mimics the effect of previous denervation, causing what they called a " pharmacological denervation" of the nictitating membrane.

The greater response of the normal side (compared with the denervated membrane) after the intravenous injection of larger amounts of 5-HT into spinal preparations may be a finding which is in parallel to the observation by Bülbring and Burn (1938) that " in some cats the response of the denervated membrane to large doses of adrenaline is less than that of the normal membrane." It may, however, also be due to a stimulation of the superior cervical ganglion by higher doses of 5-HT, which would have an additive effect.

This stimulant action on the ganglion was first observed by Robertson (1954a), who injected 1-25 $\mu \mathrm{g}$. 5-HT into the perfused superior cervical ganglion. In the present experiments 5-HT was injected intra-arterially into the blood supplying the ganglion, and it was found to stimulate about $70 \%$ of the preparations. That the contraction of the nictitating membrane was due to an action of 5-HT on the ganglion was shown by comparing the response to injections of 5-HT to the ganglion with the response to injection to the membrane. Furthermore, the action of 5-HT on the ganglion was blocked by substances which did not interfere with its direct action on the membrane.

The stimulant action of 5-HT on the ganglion was similar to that of histamine and pilocarpine, although these last two substances had no direct action on the nictitating membrane (Trendelenburg, 1954, 1955). The action of all three substances on the ganglion was abolished by the depolarizing ganglion-blocking substance nicotine, but was left unchanged by the non-depolarizing substance hexamethonium. Histamine, pilocarpine, and 5-HT were, furthermore, similar in that their ganglionic actions were reduced or abolished by the intravenous injection of cocaine in amounts which did not interfere with ganglionic transmission. However, the effect of 5-HT was less readily abolished by cocaine than that of histamine or pilocarpine.

Finally, 5-HT was similar to histamine and pilocarpine in potentiating transmission through the ganglion. This was observed not only after small amounts of 5-HT which themselves failed to cause ganglionic stimulation, but also after large amounts which stimulated the ganglion cells. There was, however, no nicotine-like paralysis even after the injection of large amounts of 5-HT. Thus it was impossible to confirm Marrazzi's observation that 5-HT blocks transmission (cit. Page and McGubbin, 1953). In spite of the absence of any nicotine- like paralysis, small amounts of 5-HT easily blocked the response to a closely following injection of 5-HT. This observation provides further evidence for the presence of tryptamine receptors in autonomic ganglia, as suggested by Gaddum (1953) and Gaddum and Hameed (1954).

5-HT differed from histamine and pilocarpine only in its not being antagonized by either atropine or mepyramine.

Konzett and Rothlin (1953) recently reviewed the action of various substances on sympathetic ganglia, on the adrenal medulla and on the carotid sinus. They came to the conclusion that for most substances there was a close parallelism in their actions on these three organs. 5-HT provides another example for this parallelism, as it is well known to stimulate the adrenal medulla (Reid and Rand, 1942 ; Lecomte, 1955) and the carotid sinus. Ginzel and Kottegoda (1954) found that the intraarterial injection of 5-HT close to the carotid sinus caused a fall of blood pressure, which was not prevented by hexamethonium and which was abolished after cutting the sinus nerve. In this connexion it may be of interest to point out that, as Fig. 4 shows, the hypotension after an intraarterial injection of 5-HT was similar both in magnitude and duration to the potentiation of ganglionic transmission. This observation suggests a certain similarity of the action of 5-HT on sympathetic ganglia and on the receptors of the carotid sinus.

Gaddum and Giarman (1956) have recently shown that the superior cervical ganglion is very rich in 5-hydroxytryptophan-decarboxylase, the enzyme responsible for the synthesis of 5-HT, although the ganglion does not seem to contain any appreciable store of this substance. Nothing is known about a liberation of 5-HT from structures of the ganglion, but it is an interesting fact that 5-HT can be synthesized by a ganglion on whose activity it has been found to exert a facilitating action. The potentiation of ganglionic transmission was observed regularly after the intra-arterial injection of very small amounts of $5-\mathrm{HT}(0.01-0.1 \mu \mathrm{g}$.). This modifying action on ganglionic transmission seems to be of more importance than the stimulation observed after the injection of larger amounts of 5-HT.

\section{SUMMARY}

1. When 5-HT was injected intravenously into the spinal cat the effect on the previously denervated and normal nictitating membranes depended on the dose. Small amounts caused a greater contraction of the denervated membrane, whereas 
large amounts caused a greater contraction of the normal membrane.

2. In the perfused head of the cat 5-HT had an adrenaline-like action on the nictitating membrane but was less effective than adrenaline. In this preparation 5-HT caused a larger response on the denervated than on the normal side in all doses.

3. The direct action of 5-HT on the nictitating membrane was not blocked by nicotine; it was potentiated by cocaine.

4. Intra-arterial injection of 1-100 $\mu \mathrm{g}$. 5-HT into the blood supply of the superior cervical ganglion caused stimulation of the ganglion in $70 \%$ of the preparations. This stimulation was-abolished by nicotine and by cocaine, but it was not affected by hexamethonium, atropine or mepyramine.

5. Intra-arterial injection of 5-HT into the blood supply of the ganglion potentiated the response of the nictitating membrane to submaximal preganglionic stimulation but not that to supramaximal stimulation. The potentiation of ganglionic transmission was reduced by cocaine, but was unchanged by atropine and mepyramine.

6. The results are taken as evidence for the presence of tryptamine receptors in the superior cervical ganglion.
I wish to express my thanks to Professor J. H. Burn for his advice and guidance throughout this work, and to Mr. H. W. Ling for his very careful assistance with the perfusion experiments. I am indebted to Dr. H. W. Barber, of Messrs. May \& Baker Ltd., for a supply of 5-hydroxytryptamine.

\section{REFERENCES}

Bülbring, E., and Burn, J. H. (1938). J. Physiol., 91, 459. Burn, J. H., and Trendelenburg, U. (1954). Brit. J. Pharmacol., 9, 202.

Erspamer, V. (1954). Rendiconti scientifici farmitalia, $1,68$.

Fleckenstein, A., and Bass, H. (1953). Arch. exp. Path . Pharmak., 220, 143.

Gaddum, J. H. (1953). J. Physiol., 119, 363.

Gand Giarman, N. J. (1956). Brit. J. Pharmacol., $11,88$. and Hameed, K. A. (1954). Ibid., 9, 240.

Ginzel, K. H., and Kottegoda, S. R. (1954). J. Physiol., 123, 277.

Konzett, H., and Rothlin, E. (1953). Experientia, 9, 405.

Lecomte, J. (1955). Arch. int. Pharmacodyn., 100, 457.

Page, I. H., and McGubbin, J. W. (1953). Circulatory Res., 1, 354.

Reid, G., and Rand, M. (1952). Nature, Lond., 169, 801.

Robertson, P. A. (1953). J. Physiol., 121, 54P.

- (1954a). Ibid., 125, 37P.

- (1954b). Ph.D. thesis, London University.

Thompson, J. W. (1955). J. Physiol., 129, 70P.

Trendelenburg, U. (1954). Brit. J. Pharmacol., 9, 481.

- (1955). J. Physiol., 129, 337. 